\title{
АНАЛИЗ ОСОБЕННОСТЕЙ МЕСТНОГО САМОУПРАВЛЕНИЯ В ГОРОДАХ-СУБЪЕКТАХ РФ
}

\section{ANALYSIS OF FEATURES OF LOCAL SELF-GOVERNMENT IN CITIES-SUBJECTS OF THE RUSSIAN FEDERATION}

V. Zotov

Summary: Local self-government is an important component of the country's governance system and is the closest element of communication between the population and the Executive power of the state. At the same time, the structure of local self-government varies according to the scale and status of the country's territorial segments. Cities-subjects of the Russian Federation, including Moscow, Saint Petersburg and Sevastopol, have a different management system than other cities, which is due to the peculiarities of the state mechanism in these regions. The article provides a comparative analysis of the features of local selfgovernment in the cities-subjects of the Russian Federation, systematizes the differences from the formed management system in other cities of Russia. It is essential to consider the features of local self-government in each of them in order to identify problems and solutions in the further development of self-government.

Keywords: local government, budget, revenues, expenses, structure, mechanism.
B результате реформирования системы территориально-административного деления в Российской Федерации были выделены города, сочетающие в себе признаки субъектов страны. Таким городам был присвоен статус федерального значения, что обусловило необходимость выработки механизма местного самоуправления в данных территориях, учитывая их масштабность и внутри территориальное деление. Речь идет о Москве, Санкт-Петербурге и Севастополе. Стоит отметить, что местное самоуправление в городах-субъектах РФ, как и других муниципальных образованиях имеет следующие законодательные рамки:

- Европейская хартия местного самоуправления [1],

- Конституция РФ [2];

- Федеральный закон от 06.10.2003 131-Ф3 «О6 общих принципах организации местного самоуправления в Российской Федерации» [3].

В Хартии определены разнообразные требования к реализации права граждан на осуществление местного самоуправления. Прежде всего это признание того факта, что органы местного самоуправления являются одной из главных основ демократического строя, и что они
Зотов Владимир Борисович

Д.э.н., профессор, ФГБУ ВО «Государственный университет управления» (Москва) ZotovVB@mail.ru

Аннотация: Местное самоуправление является важной составляющей системы управления страной и представляет собой ближайший элемент коммуникаций между населением и исполнительной властью государства. При этом устройство местного самоуправления различно в соответствии с масштабами и статусом территориальных сегментов страны. Городам-субъектам РФ, среди которых Москва, Санкт-Петербург и Севастополь свойственна система управления, отличная от других город, что связано с особенностями государственного механизма в данных регионах. В статье приведен сравнительный анализа особенностей местного самоуправления в городах-субъектах РФ, систематизированы отличия от сформированной системы управления в других городах России. Принципиально важно рассмотреть особенности местного самоуправления в каждом из них, чтобы выявить проблемы и пути решения в дальнейшем развитии самоуправления.

Ключевые слова: местное самоуправление, бюджет, доходы, расходы, структура, механизм.

должны быть наделены «значительной самостоятельностью в отношении полномочий, порядка их осуществления и средств, необходимых для выполнения своих функций».

В Конституции же - в основной главе 1 - уточняется, что в России есть государственная и муниципальная власть, и последняя пользуется самостоятельностью (ст.12).

С учетом последних правок в Конституцию РФ было введено новое основополагающее понятие - понятие публичной власти, которое ранее в Основном законе еще не употреблялось. В тексте хартии есть только термин «публичные дела», но единой системы там нет - наоборот, подчеркивается автономность самоуправления.

Изучая опыт зарубежных стран, Правительством города Москвы было принято решение о делении Административных округов мегаполиса на так называемые внутригородские муниципальные образования - поселения, в составе которых выделены отдельные территории, четко отграниченные планом градостроительства и землеустройства города Москва. При этом такие 
муниципальные образования отличаются от обычных поселений и малых городов, входящих в структуру муниципального управления. В тоже время, в современных условиях отсутствует четко проработанная нормативноправовая база подобных административно-территориальных единиц, определяющая особенности формирования их бюджетов. К тому же в настоящее время не проработан статус внутригородских поселений ни в Ф3 131-Ф3 «Об общих принципах организации местного самоуправления в РФ» [3], ни в Бюджетном Кодексе РФ [4], Законе города Москвы от 6.11.2002 № 56 «Об организации местного самоуправления в городе Москве» [5].

Система управления в районах города Москвы приведена на рисунке 1.

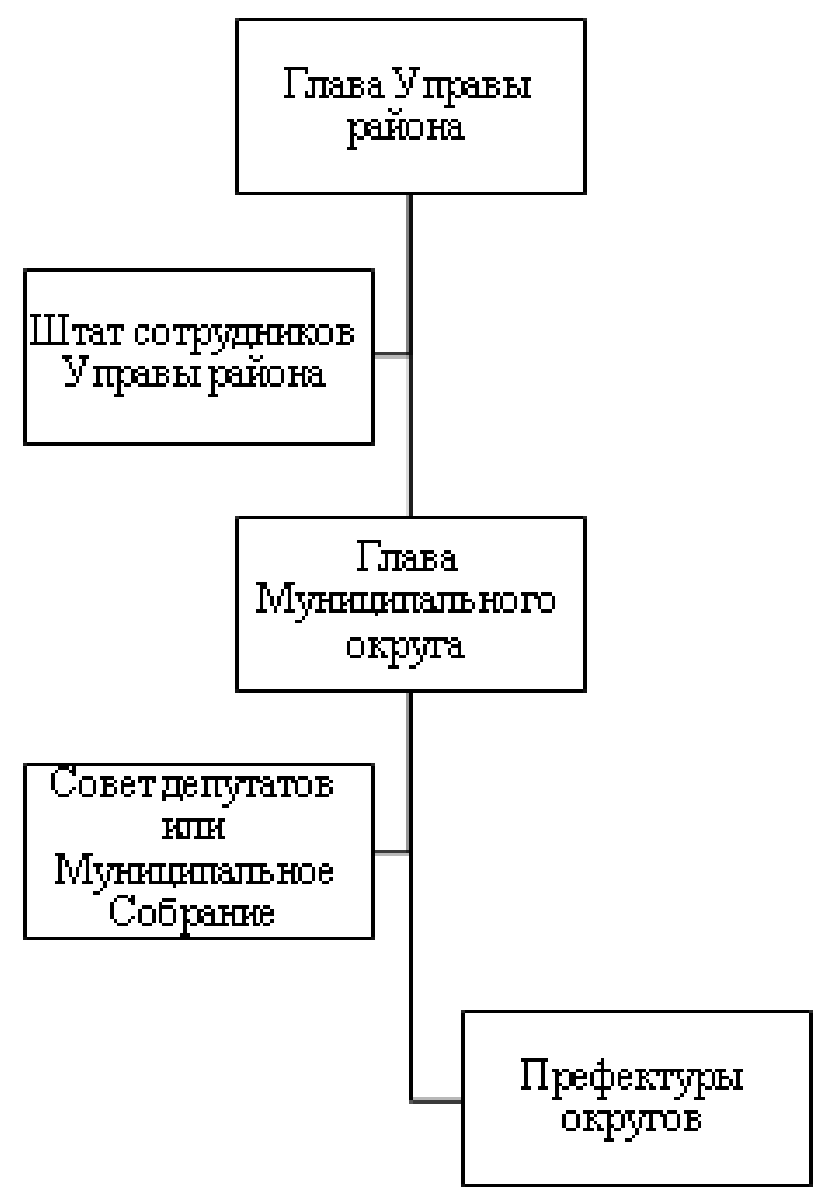

Рис. 1. Система управления в муниципальных районах города Москвы [3]

В результате наличия недостатков в нормативной базе, внутригородские муниципальные образования сталкиваются с проблемами администрирования местных налогов, а также ошибками в управлении муниципальным имуществом. Имеют место и другие недостатки, снижающие доходный потенциал муниципальных образований Москвы.
Абсурдность ситуации в целом определяется и наличием двух центров власти в московских районах, когда две команды управляющих находятся в одном районе: одна команда служащих работает в Управе, другая команда - в муниципалитете. Понятно, что одна из задач Управы района - обеспечивать функционирование общегородского хозяйства, содержание и эксплуатацию жилого фонда района, оказывать социальные и другие услуги населению. При этом Совет депутатов, аппарат Совета депутатов или как в некоторых районах - муниципалитет, обладают лишь малыми полномочиями.

Ещё один негативный момент заключается в том, что Московской городской Думой принят Закон города Москва, регулирующий отношения депутатов местного самоуправления и Департамента капремонта города Москва. В соответствии с этой нормой депутаты органов местного самоуправления подотчётны Департаменту капремонта в части приёмки объёмов капитальных работ в ЖКХ. Для улучшения системы административного управления в городе Москва необходимо провести оптимизацию и модернизацию местного самоуправления в городе Москва. На районном уровне необходимы исполнительные органы власти местного самоуправления и представительные органы власти местного самоуправления. Следовательно, административное управление районами города Москва может выглядеть следующим образом (рисунок 2).

Что касается существования префектур административных округов города Москва, то, можно с уверенностью считать, что свою функцию в период становления современных органов управления Москвой они выполнили и подлежат упразднению. Таким образом, система местного самоуправления в Москве имеет недостатки в административном плане и контексте распределения полномочий между участниками местного самоуправления.

В свою очередь, местное самоуправление в городе Санкт-Петербург реализуется в границах внутригородских муниципальных образований, исходя из имеющихся интересов населения соответствующих внутригородских муниципальных образований Санкт-Петербурга.

В соответствии с законом Санкт-Петербурга от 25.07.2005 №411-68 «О территориальном устройстве Санкт-Петербурга» [6], территория Санкт-Петербурга разделена на 18 районов.

В границах районов располагаются 111 муниципальных образования, 81 муниципальный округ (некоторым из них присвоены названия, некоторые называются по номерам), 9 городов и 21 посёлок городского типа.

В Санкт-Петербурге установлено 2 уровня в системе 
органов государственной власти - уровень города и уровень района. Государственная власть на городском уровне реализуется на основании Устава, принятого 14 января 1998 года Законодательным собранием города. Высшим должностным лицом города при этом является Губернатор. Наглядно схема местного самоуправления города Санкт-Петербург приведена на рисунке 3.

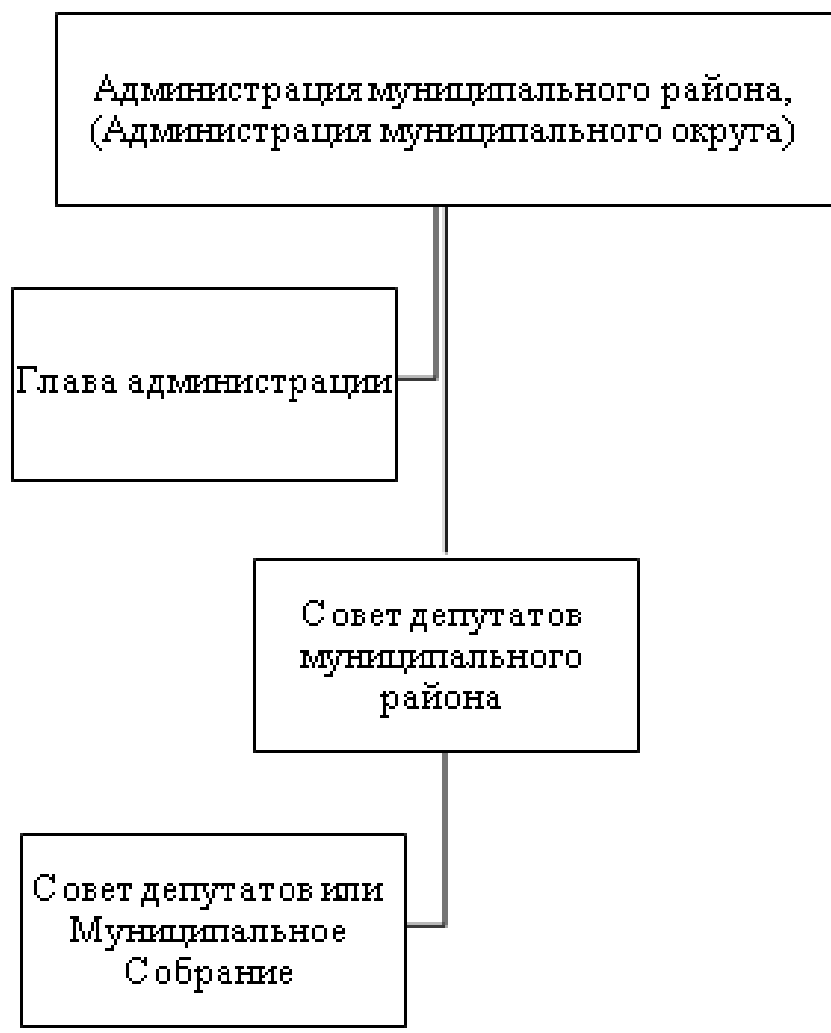

Рис. 2. Возможная схема системы управления в муниципальных районах города Москва (составлено автором)

Стоит пояснить, что муниципальные образования в самом городе располагаются внутри территориальных границ административных районов города. При этом в Санкт-Петербурге сформированы общегородские органы государственной власти.

Несмотря на видимую слаженность, в системе местного самоуправления города Санкт-Петербург также имеет место множество проблем, среди которых несогласованность работы между региональными и муниципальными властями, отсутствие координации, непрочное финансовое положение муниципалитетов и др. К тому же в результате пандемии в 2020 году 111 муниципальных образований Петербурга провели значительную корректировку бюджетов, значительно сократив расходы. Так в результате ухудшения экономической ситуации, а также планируемого сокращения ставки по упрощённой системе налогообложения (УСН) с 6 до 3\% для части субъектов малого бизнеса выпала значительная часть доходов муниципальных бюджетов.
Согласно данных комитета финансов города СанктПетербург, поступления по УСН в 2020 году должны были принести местным бюджетам 5,47 млрд рублей, что составляет 55,3\% от их налоговых доходов. При этом размер консолидированного бюджета всех муниципалитетов Петербурга в 2019 году оценивался в 13 млрд рублей [7]. Однако в результате общего ухудшения экономической ситуации доходы муниципалитетов снизились почти в 2 раза. В этих условиях региональному бюджету целесообразно сформировать схему поддержки муниципалитетов. Выход видится в передаче полномочий на распределение доходов НДФЛ, поступающего в бюджет Санкт-Петербурга в размере 0,1\%.

Еще один город-субъект в РФ - это Севастополь, который, несмотря на небольшие размеры, имеет важное геополитическое значение для страны. Однако его особый статус создает ряд проблем, связанных с системой местного самоуправления. Статус города усиливается наличием крупного объекта Министерства обороны - базы Черноморского флота, нахождение которой не может не накладывать отпечаток на стратегию развития города [8].

Полномочия города федерального значения в какойто степени влияют на конфликт между желанием населения принимать большее участие в решении вопросов местного значения и жестким контролем со стороны федерального центра. В Севастополе конфронтация отдельных уровней власти связана с недостаточной степенью автономности местного самоуправления. Местный бюджет Севастополя не наделен полномочиями в распределении доходов от поступающих в регион налогов и платежей. При этом зачастую местные власти не имеют возможности провести элементарные ремонтные работы по благоустройству города.

В целом стоит отметить, что конфликт между самоуправлением территорией и необходимостью исполнения государственных функций присущ всем городамсубъектам РФ, поскольку в конституции Российской Федерации и законе о местном самоуправлении недостаточно детально прописаны все особенности осуществления МСУ в субъектах. Конфигурация муниципалитетов и уровень их полномочий различаются во всех городах федерального значения: Санкт-Петербурге, Москве и Севастополе. При этом наиболее эффективной моделью, по нашему мнению, является модель СанктПетербурга, в котором вопросы благоустройства придомовых территорий, ухода за парками и скверами отданы органам местного самоуправления. Более того, у них есть такие полномочия как содействие развитию и образованию музеев, это очень важно для всех городов федерального значения.

В заключение стоит отметить, что все города феде- 


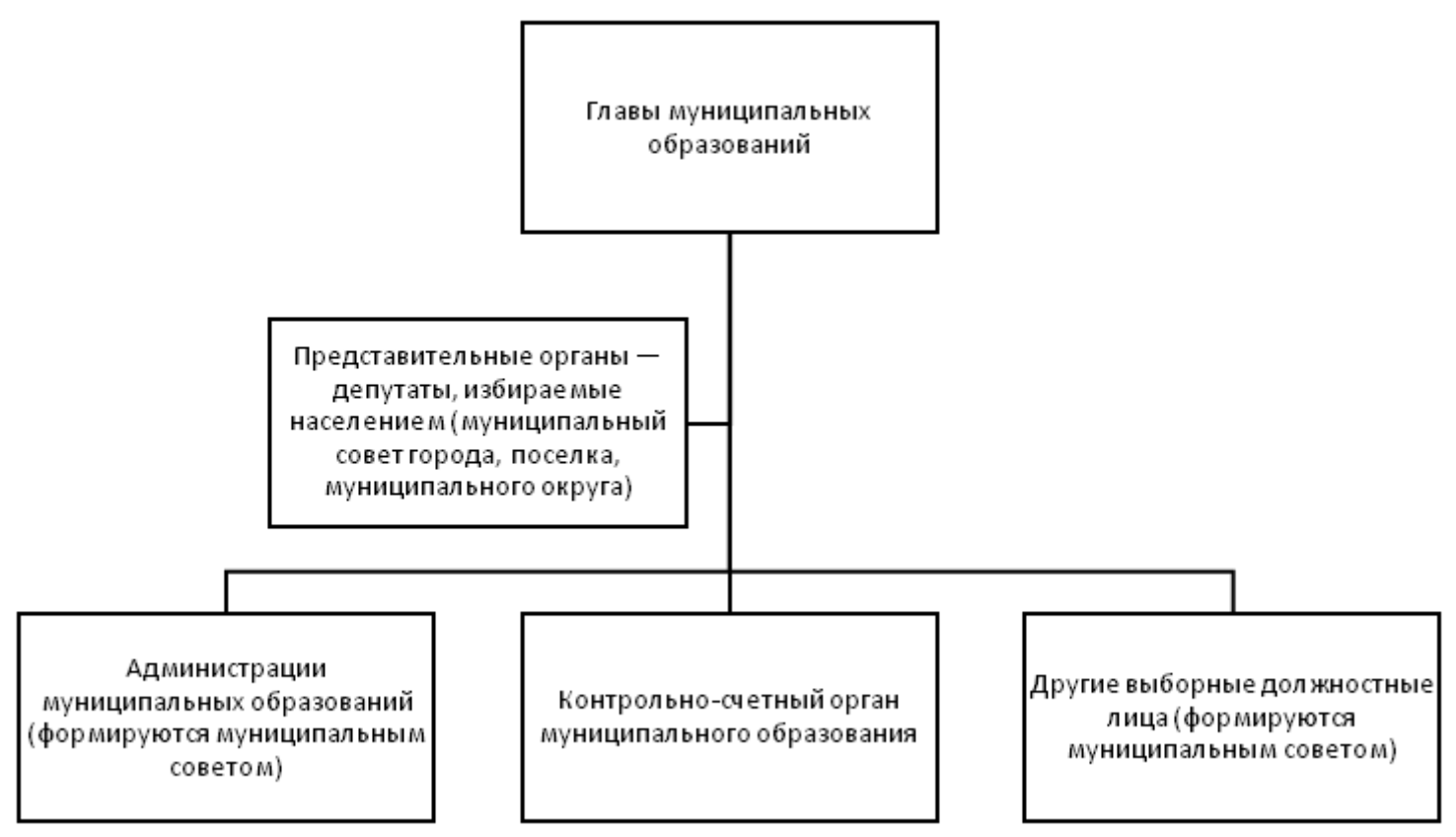

Рис. 3. Структура органов местного самоуправления г. Санкт-Петербург [6]

рального значения имеют отличия в системе их местного самоуправления, которая к тому же, существенно различается от муниципальных образований страны общего уровня. Так Москве свойственна многоуровневая система местного самоуправления, отливающая ее от других субъектов более низкой степенью самостоятельности муниципальных образований внутри региона и зависимость их от каждого вышестоящего уровня.

В Севастополе система местного самоуправления представлена в целом, как представительный орган, не имеющий особых полномочий.

В Санкт-Петербурге сформирована максимально эффективная модель местного самоуправления, которая может быть тиражирована и на другие субъекты.
В тоже время местному самоуправлению стоит проработать более четкую правовую регламентацию, устанавливающую степень автономности данной системы. К тому же необходимо и усиление финансовой независимости данных субъектов от вышестоящих бюджетов, которая, безусловно, должна находился под высокой степенью контроля. Эффективная система самоуправления является важным элементам коммуникации между населением и властью муниципальных образовании, что еще раз доказывает значимость в ее преобразовании. Наиболее эффективной является такая модель, при которой любой житель может обратиться к представителям местной власти за решением текущих проблем в части благоустройства, ЖКХ, образования и других, получив при этом помощь в кратчайшие сроки.

\section{ЛИТЕРАТУРА}

1. Европейская хартия местного самоуправления ETS N 122 (Страсбург, 15 октября 1985 г.) // Собрание законодательства Российской Федерации, N 36,7 сентября 1998 года, ст. 4466.

2. Конституция Российской Федерации (принята всенародным голосованием 12.12.1993 с изменениями, одобренными в ходе общероссийского голосования 01.07.2020) // Собрание законодательства Российской Федерации, N 31, 04.08.2014, ст.4398.

3. Федеральный закон от 6 октября 2003 г. N 131-Ф3 «06 общих принципах организации местного самоуправления в Российской Федерации» (ред. от 20.07.2020) // Собрание законодательства Российской Федерации, N 40, 06.10.2003, ст.3822

4. Бюджетный кодекс Российской Федерации от 31.07.1998 N 145-Ф3 (ред. от 31.07.2020) // Собрание законодательства Российской Федерации, N 31 , 03.08.98, ст.3823

5. Закон г. Москвы от 06.11.2002 N 56 (ред. от 20.11.2019) «06 организации местного самоуправления в городе Москве // Ведомости Московской городской думы, N 12, 2002

6. Закон Санкт-Петербурга от 25.07.2005 №411-68 (ред. от 01.01.2020) «0 территориальном устройстве Санкт-Петербурга» // Вестник Администрации Санкт-Петербурга, N 8, 29.08.2005

7. Закон Санкт-Петербурга от 08.04.2020 № 201-45 «0 внесении изменений в отдельные законы Санкт-Петербурга о налогах и сборах» // 0фициальный сайт 
Администрации Санкт-Петербурга www.gov.spb.ru/norm_baza/npa, 26.02.2020

8. Постановление Правительства Севастополя от 23.11.2016 № 1130-ПП (ред. от 07.08.2020) «Развитие гражданского общества и создание условий для обеспечения общественного согласия в городе Севастополе» // Официальный сайт Правительства Севастополя http://sevastopol.gov.ru, 23.11.2016.

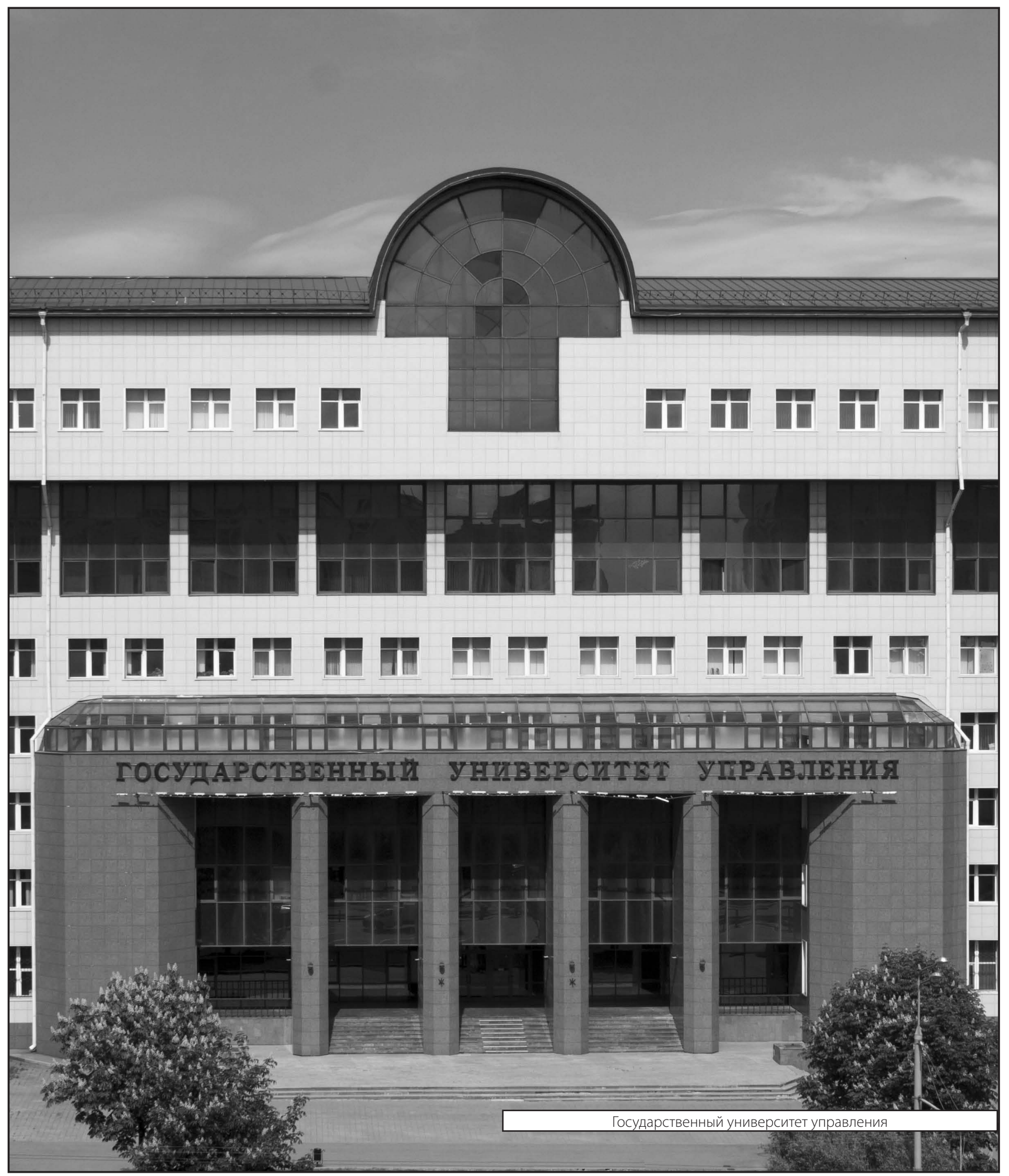

